\title{
A randomized control trial to evaluate the effect of adjuvant selective laser trabeculoplasty versus medication alone in primary open-angle glaucoma: preliminary results
}

This article was published in the following Dove Press journal:

Clinical Ophthalmology

25 September 2014

Number of times this article has been viewed

Jacky WY Lee ${ }^{1,2}$

Catherine WS Chan ${ }^{2}$

Mandy OM Wong ${ }^{3}$

Jonathan $\mathrm{CH} \mathrm{Chan}{ }^{3}$

Qing $\mathrm{Li}^{2}$

Jimmy SM Lai

'The Department of Ophthalmology, Caritas Medical Centre,

${ }^{2}$ The Department of Ophthalmology,

The University of Hong Kong,

${ }^{3}$ The Department of Ophthalmology,

Queen Mary Hospital, Hong Kong
Correspondence: Jacky WY Lee

The Department of Ophthalmology,

Caritas Medical Centre, III Wing Hong

Street, Kowloon, Hong Kong

Tel +852340879 II

Fax+85223070582

Email jackywylee@gmail.com
Background: The objective of this study was to investigate the effects of adjuvant selective laser trabeculoplasty (SLT) versus medication alone on intraocular pressure (IOP) control, medication use, and quality of life in patients with primary open-angle glaucoma.

Methods: This prospective, randomized control study recruited 41 consecutive primary openangle glaucoma subjects with medically-controlled IOP $\leq 21 \mathrm{mmHg}$. The SLT group ( $\mathrm{n}=22)$ received a single 360-degree SLT treatment. The medication-only group $(n=19)$ continued with their usual treatment regimen. In both groups, medication was titrated to maintain a target IOP defined as a $25 \%$ reduction from baseline IOP without medication, or $<18 \mathrm{mmHg}$, whichever was lower. Outcomes, which were measured at baseline and at 6 months, included the Glaucoma Quality of Life-15 (GQL-15) and Comparison of Ophthalmic Medications for Tolerability (COMTOL) survey scores, IOP, and the number of antiglaucoma medicines.

Results: The baseline IOP was $15.8 \pm 2.7 \mathrm{mmHg}$ and $14.5 \pm 2.5 \mathrm{mmHg}$ in the SLT and medicationonly groups, respectively $(P=0.04)$. Both groups had a comparable number of baseline medication $(P=0.2)$ GQL-15 $(P=0.3)$ and COMTOL scores $(P=0.7)$. At 6 months, the SLT group had a lower IOP $(P=0.03)$ and required fewer medications compared with both baseline $(P<0.0001)$ and with the medication-only group $(P=0.02)$. There was no statistically significant difference in the 6-month GQL-15 or COMTOL score as compared to baseline $(P \geq 0.4)$ or between the two treatment groups $(P \geq 0.2)$.

Conclusion: A single session of adjuvant SLT provided further reductions in IOP and medication without substantial changes in quality of life or medication tolerability at 6 months.

Keywords: quality of life, intraocular pressure, antiglaucoma medication

\section{Introduction}

Primary open-angle glaucoma (POAG) is characterized by a progressive glaucomatous optic neuropathy. One of the most recognized risk factors associated with POAG is elevated intraocular pressure (IOP), ie, $\geq 21 \mathrm{mmHg}$. Accordingly, many patients require multiple antiglaucoma medications to regulate IOP. Although medication may provide adequate IOP control, it is associated with numerous side effects and may even compromise patients' quality of life (QoL). Additionally, because antiglaucoma drops are somewhat inconvenient to use, treatment compliance is a significant issue. ${ }^{1}$

Selective laser trabeculoplasty (SLT) is a noninvasive laser procedure that can increase aqueous outflow by increasing the porosity of the trabecular meshwork from the upregulation of metalloproteinases, cytokines, and macrophages. ${ }^{2}$ SLT offers similar long-term IOP-lowering effects as medical therapy alone but has minimal adverse 
effects. Moreover, because SLT does not cause collateral damage to the surrounding tissue, it can be repeated. ${ }^{3}$ SLT also has the potential to reduce antiglaucoma medication use, which may potentially improve patients' QoL. ${ }^{4}$

The Early Manifest Glaucoma Trial demonstrated that there was no significant difference in health-related QoL between patients treated with a topical beta-blocker plus argon laser trabeculoplasty versus no treatment in newlydiagnosed POAG patients. ${ }^{5}$ Additionally, the Collaborative Initial Glaucoma Treatment Study showed no substantial difference in QoL between those treated with medication versus filtration surgery in newly-diagnosed POAG patients. $^{6}$

Currently, published literature evaluating the role of adjuvant SLT for POAG patients who are already on antiglaucoma medication is somewhat limited. Consequently, the aim of the study was to investigate the efficacy of adjuvant SLT versus medication alone in terms of IOP control, medication requirement and tolerability, and glaucoma-specific QoL in patients with POAG.

\section{Patients and methods}

This was a prospective, randomized controlled study conducted at a university hospital in Hong Kong, from June 2012 to March 2013. Ethics approval by the institutional review board was obtained prior to study commencement, and all patients were required to provide written informed consent. The study was registered with the Clinical Trials Register of the University of Hong Kong (HKCTR-1597) and complied with the principles outlined in the Declaration of Helsinki. ${ }^{7}$

The inclusion criteria consisted of consecutive subjects aged $\geq 18$ years, with preexisting bilateral POAG with IOP medically-controlled to $\leq 21 \mathrm{mmHg}$. POAG was defined as an open angle on gonioscopy, presenting IOP $\geq 21 \mathrm{mmHg}$, and visual field loss on the Humphrey visual field analyzer as per the Hodap-Parrish-Anderson criteria, ${ }^{8}$ or retinal nerve fiber layer thinning on optical coherence tomography. All subjects were using at least one antiglaucoma medication in each eye prior to study recruitment. The exclusion criteria included those with secondary glaucomas, angle-closure glaucomas, a follow-up history of less than 6 months, illiteracy, and previous laser or surgical procedure for glaucoma. SLT was offered for patients with the aim of reducing the number of antiglaucoma medications required.

In both groups, an individual target IOP was determined as a $25 \%$ reduction in IOP from the first presentation (before the use of antiglaucoma medication), as per the findings of the Early Manifest Glaucoma Trial, ${ }^{9}$ or an IOP $<18 \mathrm{mmHg}$ as per the Advanced Glaucoma Intervention Study, ${ }^{10}$ whichever was lower.

Subjects were randomized into two groups (the SLT group and the medication-only group) based on a computergenerated random sequence. The SLT group received a single SLT treatment via a Q-switched Nd:YAG laser (Ellex Solo ${ }^{\text {TM}}$; Ellex Medical Pty. Ltd., Adelaide, Australia), with initial energy of $0.8 \mathrm{~mJ}$ and titrated until bubble formation was just visible. Treatment was delivered by a single glaucoma specialist (JWYL), in a single burst mode to 360 degrees of the trabecular meshwork. Both eyes were treated in the same laser session. In all treated eyes, a drop of Alphagan $P$ (Allergan Inc., Waco, TX, USA) was instilled post-SLT, and a dexamethasone $0.1 \%$ and neomycin $0.5 \%$ combination eye drop (Dexoptic-N; Ashford Laboratories Pvt. Ltd., Mumbai, India) was used twice daily for 1 day, although treatment was continued for several days if anterior chamber reaction was seen 1 day post-SLT. Subjects returned for follow-up at 1 day, 1 week, and 1 month after SLT, and every 3 months thereafter.

Subjects continued on the same pre-SLT antiglaucoma eye drops post-SLT. At 1 month postoperatively, antiglaucoma eye drops were titrated based on the individual clinical response in order to reach their target IOP as detailed above. The medication-only group continued their current antiglaucoma eye drops with titrations made to their current regimen to maintain their target IOP during follow-up every 3 months. In both groups, medications were added in the following sequence if the target IOP was not met: prostaglandin analogues or beta-blockers, followed by alpha-adrenergic agonist or topical carbonic anhydrase inhibitor, then pilocarpine. Likewise, if the IOP was well below the target IOP, medications were removed in the following sequence: pilocarpine, followed by alpha-adrenergic agonist or topical carbonic anhydrase inhibitor, then prostaglandin analogues or beta-blockers. Where required, fixed combination eye drops were prescribed to simplify drug regimens and were counted as two types of medication in the analysis. Medications were changed either to improve IOP control or in cases of reported drug intolerance.

Traditional Chinese translated versions of the Glaucoma Quality of Life-15 (GQL-15) and the Comparison of Ophthalmic Medications for Tolerability (COMTOL) surveys were completed by all subjects at baseline and at 6 months.

The GQL-15 questionnaire is a glaucoma-specific, written questionnaire that assesses patients' perceived visual disability in 15 daily tasks. The tasks are categorized in four areas of visual disability: 1) central and near vision, 
2) peripheral vision, 3) dark adaptation and glare, and 4) outdoor mobility. A 5-point rating scale for the level of difficulty of each task totals a score from 0 to 75 . A higher score signifies a poorer QoL (Table 1).

The COMTOL questionnaire is a consistent, reliable, and reproducible assessment of the local side effects of topical antiglaucoma medications. ${ }^{11-13} \mathrm{We}$ simplified the original COMTOL by eliminating the subscales that further quantified the degree of severity and frequency of the side effects. Patients were simply asked to identify whether or not they had experienced any of the 15 local side effects from the COMTOL checklist to produce a "side effects score" from 0 to 15 . A higher score signifies a greater intolerability to the medication (Table 2).

The questionnaires were translated from English to Chinese by an investigator who was fluent in both languages followed by a back translation by another investigator. To then ensure the accuracy of the translation, the translated questionnaire was tested on five POAG patients of varying sex and age. Patients were asked to complete the questionnaires in addition to offering their interpretation of the contents in the questionnaire and were invited to suggest alternative wording if necessary.

In addition to GQL-15 and COMTOL scores, the main outcome measures were IOP and the number of antiglaucoma medications used at baseline and 6 months. All IOPs were measured by a single observer using Goldmann applanation tonometry either on Tuesday afternoons or Thursday mornings, and patients were advised to return for follow-up during the same time periods to minimize diurnal variability. To limit bias, the observer attempted to record the IOP prior to studying the patient's medical records.

\section{Statistical analysis}

Statistical calculations were performed using GraphPad Prism 5.0 (GraphPad Software, Inc., La Jolla, CA, USA). The Mann-Whitney $U$-test and the Wilcoxon signed rank test were used to compare differences in IOP, GQL-15, COMTOL, and number of antiglaucoma medications at baseline and 6 months between the SLT and the medicationonly group. Based on the sample size of 41 patients, a $40 \%$ difference in the number of medications used at 6 months between the two treatment arms, and an alpha error of 0.05 , the calculated power of this study was $86.4 \%$. All means were expressed as mean \pm standard deviation. Statistical significance was defined as $P<0.05$.

\section{Results}

The study included 41 patients, 22 in the SLT group and 19 in the medical group. Demographic and baseline characteristics for both groups are described in Table 3 .

The SLT group received 121.8 \pm 30.0 laser shots at a mean energy of $0.9 \pm 0.05 \mathrm{~mJ}$. There were no complications from the laser procedure. At 1 day, 1 week, and 1 month post-SLT, IOPs were $11.9 \pm 2.5 \mathrm{mmHg}, 13.6 \pm 3.3 \mathrm{mmHg}$, and $13.6 \pm 2.9 \mathrm{mmHg}$, respectively.

At 6 months, the IOP in the SLT group $(13.4 \pm 2.3 \mathrm{mmHg})$ had reduced by $15.2 \%$ from baseline $(P<0.0001)$ and was $7.6 \%$ lower than the medication-only group $(P=0.03)$ (Table 4$)$. Compared to baseline, the overall IOP reduction was $40.9 \%$ in the SLT group and $41.9 \%$ in the medication-only group.

At 6 months, the SLT group required 34.8\% fewer number of antiglaucoma medications compared to baseline $(P<0.0001)$ and $40.0 \%$ fewer antiglaucoma eye drops compared to the medication-only group (Table 4$)$. The most

Table I The Glaucoma Quality of Life- I5 questionnaire

\begin{tabular}{|c|c|c|c|c|c|c|}
\hline $\begin{array}{l}\text { Does your vision give you any difficulty, even } \\
\text { with glasses, with the following activities? }\end{array}$ & None & A little bit & Some & Quite a lot & Severe & $\begin{array}{l}\text { Do not perform } \\
\text { for nonvisual reasons }\end{array}$ \\
\hline Reading newspapers & I & 2 & 3 & 4 & 5 & 0 \\
\hline Walking after dark & I & 2 & 3 & 4 & 5 & 0 \\
\hline Seeing at night & I & 2 & 3 & 4 & 5 & 0 \\
\hline Walking on uneven ground & I & 2 & 3 & 4 & 5 & 0 \\
\hline Adjusting to bright lights & I & 2 & 3 & 4 & 5 & 0 \\
\hline Adjusting to dim lights & I & 2 & 3 & 4 & 5 & 0 \\
\hline Going from light to dark room or vice versa & I & 2 & 3 & 4 & 5 & 0 \\
\hline Tripping over objects & l & 2 & 3 & 4 & 5 & 0 \\
\hline Seeing objects coming from the side & I & 2 & 3 & 4 & 5 & 0 \\
\hline Crossing the road & I & 2 & 3 & 4 & 5 & 0 \\
\hline Walking on steps/stairs & I & 2 & 3 & 4 & 5 & 0 \\
\hline Bumping into objects & I & 2 & 3 & 4 & 5 & 0 \\
\hline Judging distance of foot to step/curb & I & 2 & 3 & 4 & 5 & 0 \\
\hline Finding dropped objects & I & 2 & 3 & 4 & 5 & 0 \\
\hline Recognizing faces & I & 2 & 3 & 4 & 5 & 0 \\
\hline
\end{tabular}


Table 2 Comparison of ophthalmic medications for tolerability checklist

Burning
Blurred vision
Tearing
Itchy eyes
Dimming of vision
Discharge from eyes
Focusing
Reading
Redness
Bitter taste
Swelling
Dry eyes
Trouble seeing at night
Unusual taste
Brow ache

commonly used antiglaucoma medications were prostaglandin analogues and beta-blockers in both treatment arms at baseline and 6 months (Table 5).

The 6-month GQL-15 score was similar between the SLT (23.7 \pm 9.0$)$ and the medication-only groups $(28.0 \pm 12.5)$ $(P=0.2)$, and there was no significant improvement from baseline scores in either group $(P>0.4)$ (Table 4). The 6-month COMTOL score was also similar between the SLT (3.7 \pm 3.6$)$ and medication-only group (4.7 \pm 4.4$)(P=0.5)$. As per GQL-15, there was no significant improvement from baseline scores in either group $(P>0.6)$ (Table 4).

\section{Discussion}

To the best of our knowledge, this is one of the first randomized control trials comparing QoL in POAG patients treated with adjuvant SLT versus medication alone. All subjects in our study had preexisting POAG that was medically controlled with antiglaucoma eye drops. The baseline IOP was

Table 3 Demographic and baseline characteristics between the SLT and medical group

\begin{tabular}{llll}
\hline Parameters & SLT group & Medical group & P-value \\
\hline Age (years) & $66.5 \pm 13.6$ & $65.5 \pm 12.7$ & 0.9 \\
Sex (M:F) & $1.2: 1$ & $1.1: 1$ & 0.9 \\
$\begin{array}{l}\text { Presenting IOP } \\
\text { (without medication) }\end{array}$ & $22.7 \pm 3.7 \mathrm{mmHg}$ & $25.0 \pm 4.3 \mathrm{mmHg}$ & 0.04 \\
Baseline IOP & $15.8 \pm 2.7 \mathrm{mmHg}$ & $14.5 \pm 2.5 \mathrm{mmHg}$ & 0.04 \\
Types of & $2.3 \pm 1.1$ & $2.1 \pm 0.9$ & 0.3 \\
antiglaucoma eye & & & \\
drops at baseline & & & \\
GQL-I5 score & $25.3 \pm 12.7$ & $29.1 \pm 12.1$ & 0.3 \\
COMTOL score & $4.2 \pm 3.0$ & $4.6 \pm 4.0$ & 0.7 \\
\hline
\end{tabular}

Abbreviations: COMTOL, Comparison of Ophthalmic Medications for Tolerability survey; F, female; GQL, Glaucoma Quality of Life questionnaire; IOP, intraocular pressure; M, male; SLT, selective laser trabeculoplasty. slightly higher in the SLT group, with both groups requiring approximately two types of antiglaucoma eyes drops. However, at 6 months, the SLT group had a 7.6\% lower IOP and required $40.0 \%$ less medication compared to the medical group. Both the SLT (40.9\%) and the medication-only group $(41.9 \%)$ achieved a similar percentage of IOP reduction compared to their IOP on first presentation.

QoL questionnaires in glaucoma can be categorized into general health-related, vision-specific, or glaucoma-specific. ${ }^{14}$ Of the 18 different glaucoma-specific patient-reported QoL assessments available, the GQL-15 and the Vision Quality of Life Index are more favorable in terms of their content, validity, and reliability. ${ }^{15}$ The GQL-15 assesses four areas of visual disability: 1) central and near vision, 2) peripheral vision, 3) dark adaptation and glare, and 4) outdoor mobility. In both the SLT and medical group, dark adaptation was the area of greatest difficulty, namely the task of "seeing at night." At baseline, both treatment groups had a similar GQL-15 score. At 6 months, the GQL-15 score was reduced by $6.3 \%$ in the SLT group and $3.7 \%$ in the medical group as compared to baseline although this difference was not statistically significant. Additionally, there was no significant difference between the two treatment groups at 6 months.

Given the statistically significant reduction in IOP and antiglaucoma eye drops in the SLT group, we had expected an improvement in QoL from baseline or at least in comparison with the medical group at 6 months, but this was not the case. This finding can be explained by the fact that the existing glaucoma-specific surveys including the GQL-15 may not be sensitive enough to fully account for the contributions of reduced antiglaucoma medication or lowered IOP in relation to QoL, especially when the drop in IOP occurs within a normal pressure range of $\leq 21 \mathrm{mmHg}$. It is also possible that the design of these glaucoma-specific surveys focus primarily on changes in vision, visual field, and dark adaptations, rather than on patient's satisfaction with antiglaucoma drugs. Hence, we supplemented the GQL-15 with the COMTOL checklist to investigate the side effects and tolerability of antiglaucoma eye drops.

There is limited data in the literature reporting a direct association between the side effects of topical antiglaucoma medication and QoL. Nordmann et $\mathrm{al}^{13}$ reported that $62.4 \%$ of patients had at least one local side effect from topical antiglaucoma medications. Specifically, 25.4\% had burning, $20.8 \%$ had blurring, and $20.2 \%$ had tearing after use, resulting in low treatment satisfaction and poorer QoL. Skalicky et al ${ }^{16}$ also reported that $59 \%$ of glaucoma patients had Ocular Surface Disease (OSD) due to benzalkonium chloride, the 
Table 4 SLT versus medical group at baseline and 6 months

\begin{tabular}{|c|c|c|c|c|}
\hline & & $\begin{array}{l}\text { SLT group } \\
\text { (SLT + medication) }\end{array}$ & $\begin{array}{l}\text { Medication-only } \\
\text { group }\end{array}$ & $\begin{array}{l}P \text {-value (SLT group versus } \\
\text { medication-only group) }\end{array}$ \\
\hline \multirow[t]{4}{*}{ IOP } & Baseline & $15.8 \pm 2.7 \mathrm{mmHg}$ & $14.5 \pm 2.5 \mathrm{mmHg}$ & $0.04 *$ \\
\hline & 6 months & $13.4 \pm 2.3 \mathrm{mmHg}$ & $14.5 \pm 2.2 \mathrm{mmHg}$ & $0.03 *$ \\
\hline & Change from baseline & $-15.1 \%$ & $0.0 \%$ & _- \\
\hline & $\begin{array}{l}P \text {-value (baseline vs } \\
6 \text { months) }\end{array}$ & $<0.000 I^{*}$ & 1.0 & - \\
\hline \multirow{4}{*}{$\begin{array}{l}\text { Number of } \\
\text { antiglaucoma } \\
\text { medication }\end{array}$} & Baseline & $2.3 \pm 1.1$ types & $2.1 \pm 0.9$ types & 0.3 \\
\hline & 6 months & $1.5 \pm 1.2$ types & $2.1 \pm 1.0$ types & $0.02 *$ \\
\hline & Change from baseline & $-34.8 \%$ & $0.0 \%$ & _- \\
\hline & $\begin{array}{l}P \text {-value (baseline vs } \\
6 \text { months) }\end{array}$ & $<0.000 I^{*}$ & 0.8 & - \\
\hline \multirow[t]{4}{*}{ GQL-I5 score } & Baseline & $25.3 \pm 12.7$ & $29.1 \pm 12.1$ & 0.3 \\
\hline & 6 months & $23.7 \pm 9.0$ & $28.0 \pm 12.5$ & 0.2 \\
\hline & Change from baseline & $-6.3 \%$ & $-3.7 \%$ & - \\
\hline & $\begin{array}{l}P \text {-value (baseline vs } \\
6 \text { months) }\end{array}$ & 0.4 & 0.6 & - \\
\hline \multirow[t]{4}{*}{ COMTOL score } & Baseline & $4.2 \pm 3.0$ & $4.6 \pm 4.0$ & 0.7 \\
\hline & 6 months & $3.7 \pm 3.6$ & $4.7 \pm 4.4$ & 0.5 \\
\hline & Change from baseline & $-11.9 \%$ & $2.2 \%$ & - \\
\hline & $\begin{array}{l}P \text {-value (baseline vs } \\
6 \text { months) }\end{array}$ & 0.6 & 1.0 & - \\
\hline
\end{tabular}

Note: *Represents statistical significance.

Abbreviations: COMTOL, Comparison of Ophthalmic Medications for Tolerability survey; GQL, Glaucoma Quality of Life questionnaire; IOP, intraocular pressure; SLT, selective laser trabeculoplasty; vs, versus.

preservative in eye drops, and that those with OSD had poorer glaucoma-specific QoL. The COMTOL checklist showed good-to-excellent internal consistency ( 0.73 to 0.98 ), reliability ( 0.76 to 0.94$)$, and reproducibility ( 0.75 to 0.93 ) in the assessment of medication side effects. ${ }^{11} \mathrm{We}$ found a similar pattern in the COMTOL score as with the GQL-15 score. There was an $11.9 \%$ reduction in the COMTOL score in the SLT group from baseline to 6 months and an increase of $2.2 \%$ in the medical group, but these changes were not statistically significant, nor was there a significant difference in the COMTOL scores between the two treatment groups at 6 months. With a $34.8 \%$ reduction in antiglaucoma medication use in the SLT group at 6 months compared to baseline and a $40.0 \%$ reduction in antiglaucoma medication use compared to the medication-only group at 6 months, we had expected a significant difference in the COMTOL score at 6 months for the SLT group. Our findings suggest that there may not be a direct association between medication side effects and glaucoma-specific QoL, and that patients' perceived drug tolerability and local side effects may not be directly associated with the actual number of antiglaucoma medications used. A patient with intolerance to a single medication may be very dissatisfied, while a patient on multiple antiglaucoma medications may be satisfied with the treatment if they perceive the side effects to be tolerable.

Our study clearly has several limitations. First, the randomized nature of this study produced unequal group sizes. Ideally, there would be an equal number of patients in each group; however, the use of restricted randomization or forced equality methods could potentially compromise treatment assignments and selection bias. ${ }^{17}$ Second, the translation of the original English based questionnaires was inevitable in a population where Chinese is the predominant dialect. Every effort was made to ensure that the translation was coherent

Table 5 Types of antiglaucoma medication used in both treatment arms at baseline and 6 months

\begin{tabular}{lllllll}
\hline & & $\begin{array}{l}\text { Prostaglandin } \\
\text { analogue (\%) }\end{array}$ & $\begin{array}{l}\beta \text {-blocker } \\
\text { (\%) }\end{array}$ & $\begin{array}{l}\text { Alpha-agonist } \\
\text { (\%) }\end{array}$ & $\begin{array}{l}\text { Topical carbonic } \\
\text { anhydrase inhibitor (\%) }\end{array}$ & $\begin{array}{l}\text { Pilocarpine } \\
\text { (\%) }\end{array}$ \\
\hline Baseline & SLT group & 33.3 & 33.3 & 17.6 & 13.7 & 2.0 \\
& Medication-only group & 31.4 & 34.3 & 22.9 & 11.4 & 0.0 \\
\multirow{4}{*}{6 months } & 47.1 & 32.4 & 8.8 & 11.8 & 0.0 \\
& SLT group & 40.0 & 20.0 & 10.0 & 0.0 \\
& Medication-only group & 30.0 & & &
\end{tabular}

Abbreviation: SLT, selective laser trabeculoplasty. 
with the original questionnaire both linguistically and conceptually via direct and back translations. Third, while all patients had POAG, we did not account for the differences in angle pigmentation. A pigmented angle could have improved SLT response, although the variability in an ethnic Chinese population would be minimal. Fourth, we did not account for the variability in drug adherence, which can affect the duration of exposure of medication. Fifth, the SLT group had a higher baseline IOP than the medical group and regression to the mean could have contributed to the reduction of IOP in the SLT group at 6 months. However, even if the 6-month IOPs were similar in both groups, more importantly, the SLT group required $40 \%$ less antiglaucoma medication than the medication-only group. Lastly, the titration of antiglaucoma medication was necessary for the clinical management of patients. To reduce bias, a preset individual target IOP was defined prior to the study and a medication adjustment algorithm was followed by the investigator.

Overall, our findings suggest that adjuvant SLT in those with medically-controlled POAG can further lower IOP and reduce the antiglaucoma medication required. However, there was no significant difference in the glaucoma-specific QoL or treatment tolerability when compared to their pre-SLT state, or when compared to those receiving medication alone at 6 months after treatment.

\section{Disclosure}

The authors report no conflicts of interest in this work. The article processing charge was funded by Ellex Medical Pty. Ltd. The authors had sole autonomy over all aspects of the clinical research and writeup.

\section{References}

1. Robin A, Grover DS. Compliance and adherence in glaucoma management. Indian J Ophthalmol. 2011;59 Suppl:S93-S96.

2. Katz LJ. CME: selective laser trabeculoplasty for glaucoma therapy [webpage on the Internet]. Review of Ophthalmology; 2013. Available from: http://www.revophth.com/content/d/features/i/1342/c/25695/. Accessed July 1, 2014.
3. Lai JS, Chua JK, Tham CC, Lam DS. Five-year follow up of selective laser trabeculoplasty in Chinese eyes. Clin Experiment Ophthalmol. 2004;32(4):368-372.

4. Bovell AM, Damji KF, Hodge WG, Rock WJ, Buhrmann RR, Pan YI. Long term effects on the lowering of intraocular pressure: selective laser or argon laser trabeculoplasty? Can J Ophthalmol. 2011;46(5): 408-413.

5. Heijl A, Bengtsson B, Hyman L, Leske MC; Early Manifest Glaucoma Trial Group. Natural history of open-angle glaucoma. Ophthalmology. 2009;116(12):2271-2276

6. Janz NK, Wren PA, Lichter PR, Musch DC, Gillespie BW, Guire KE. Quality of life in newly diagnosed glaucoma patients: The Collaborative Initial Glaucoma Treatment Study. Ophthalmology. 2001;108(5): 887-897; discussion 898.

7. World Medical Association. World Medical Association Declaration of Helsinki Ethical Principles for Medical Research Involving Human Subjects JAMA. 2013;310(20):2191-2194. doi:10.1001/ jama.2013.281053.

8. Hodapp E, Parrish RK II, Anderson DR. Clinical Decisions in Glaucoma. St Louis, MO: CV Mosby; 1993:52-61.

9. Heijl A, Leske MC, Bengtsson B, Hyman L, Bengtsson B, Hussein M; Early Manifest Glaucoma Trial Group. Reduction of intraocular pressure and glaucoma progression: results from the Early Manifest Glaucoma Trial. Arch Ophthalmol. 2002;120(10):1268-1279.

10. The Advanced Glaucoma Intervention Study (AGIS): 7. The relationship between control of intraocular pressure and visual field deterioration. The AGIS Investigators. Am J Ophthalmol. 2000;130(4):429-440.

11. Barber BL, Strahlman ER, Laibovitz R, Guess HA, Reines SA. Validation of a questionnaire for comparing the tolerability of ophthalmic medications. Ophthalmology. 1997;104(2):334-342.

12. Beckers HJ, Schouten JS, Webers CA, van der Valk R, Hendrikse F. Side effects of commonly used glaucoma medications: comparison of tolerability, chance of discontinuation, and patient satisfaction. Graefes Arch Clin Exp Ophthalmol. 2008;246(10):1485-1490.

13. Nordmann JP, Auzanneau N, Ricard S, Berdeaux G. Vision related quality of life and topical glaucoma treatment side effects. Health Qual Life Outcomes. 2003;1:75.

14. Spaeth G, Walt J, Keener J. Evaluation of quality of life for patients with glaucoma. Am J Ophthalmol. 2006;141(1 Suppl):S3-S14.

15. Vandenbroeck S, De Geest S, Zeyen T, Stalmans I, Dobbels F. Patientreported outcomes (PRO's) in glaucoma: a systematic review. Eye (Lond). 2011;25(5):555-577.

16. Skalicky SE, Goldberg I, McCluskey P. Ocular surface disease and quality of life in patients with glaucoma. Am J Ophthalmol. 2012; 153(1):1-9.e2.

17. Schulz KF, Grimes DA. Unequal group sizes in randomised trials: guarding against guessing. Lancet. 2002;359(9310):966-970.
Clinical Ophthalmology

\section{Publish your work in this journal}

Clinical Ophthalmology is an international, peer-reviewed journal covering all subspecialties within ophthalmology. Key topics include: Optometry; Visual science; Pharmacology and drug therapy in eye diseases; Basic Sciences; Primary and Secondary eye care; Patient Safety and Quality of Care Improvements. This journal is indexed on

\section{Dovepress}

PubMed Central and CAS, and is the official journal of The Society of Clinical Ophthalmology (SCO). The manuscript management system is completely online and includes a very quick and fair peer-review system, which is all easy to use. Visit http://www.dovepress.com/ testimonials.php to read real quotes from published authors. 